\title{
European Citizenship, Identity and Rights: A Survey on Italian Young Students
}

\author{
Tiziana Guzzo \\ Alessia D'Andrea \\ Fernando Ferri \\ Patrizia Grifoni \\ IRPPS-CNR, Italy
}

Doi:10.19044/esj.2018.v14n20p240 URL:http://dx.doi.org/10.19044/esj.2018.v14n20p240

\begin{abstract}
Developing Europe means, first of all, creating a pervasive feeling of European citizenship, and creating a sense of belonging to a community in all countries of the European Union. This paper focuses on extracting Italian students' socio-psychological dimension with respect to their perception and feelings regarding European citizenship, and their knowledge of the most relevant rights. The study involves Italian students aged between 18 and 25. A hybrid methodology has been adopted, combining: data extracted from a questionnaire; text from the photo-stories; images of the photo-stories and interviews. The results underline that young people have a sense of belonging to the European community, with the same rights and benefits. Moreover, there is the need to have the same feeling of European citizenship everywhere in Europe. The request for a stronger and more active citizens' involvement also emerged from the study.
\end{abstract}

Keywords: European citizenship, European identity, European citizens' rights, Young people, Europe

\section{Introduction}

European citizenship is a key concept of the debate that is involving policy makers, researchers, educators and citizens more and more. In recent years, strengths and weakness connected with Europe and European citizenships have been widely discussed, considering not only the economic but also cultural and political dimensions. However, this should contribute in defining both common strategies in the time of globalization of the economy and collective behaviours of society. This is with respect to the cultural and political challenges; that is, the Europe of the Economy, the Europe of Peace, the Europe of Common Rights, and the Europe of Citizens. 
Citizenship is defined as 'those who are, and who are not, members of a common society' (Barbalet, 1988, p. 1). It extends and enriches the notion of equality with civil, political values, and social rights (such as health care, public education, old-age pension and unemployment insurance).

Citizenship regimes 'serve to define who is entitled to hold the nationality of a particular country, and are often based on either jus sanguinis or jus soli, or a combination of both' (Bianchi, 2011).

Consequently, two concepts directly connected with citizenship are identity and rights (Soysal, 2000). Identity is defined as 'that part of the individual's self-concept which is derived from his knowledge of membership of a social group (or groups) together with the value and emotional significance attached to that membership' (Tajfel, 1981, p. 63). According to Brubaker and Cooper (2000), the identity concept 'is invoked to highlight the processual, interactive development of the kind of collective selfunderstanding, solidarity, or groupness that can make collective action possible'. The identity concept plays a crucial role in the European citizenship feeling. However, it is mainly connected to a common awareness of convenience in sharing a common space with common civil, political, and social rights.

Starting from the previously introduced concepts, this paper aims to discuss, from the socio-psychological perspective, European citizenship and the feeling of European identity of young Italian students, and their knowledge of the most relevant rights related to European citizenship. The focus of the study is on the Italian context. This choice is due to the rising need of Italian political Institutions to have a screening of the perception, feeling, and awareness of Italian young students of European citizenship. This is aimed to define and implement political actions focused on this topic, involving people, and increasing their awareness about rights and opportunities offered by European citizenship. The study started in 2013 within the project ' $\mathrm{Tu}$ sei l'Europa' (You are Europe) supported by the Management Partnership (consisting of the European Parliament, the European Commission, the European Affairs Department of the Presidency of the Council of Ministers and the Ministry of Foreign Affairs from Italy - in collaboration with the National Agency LLP). It was implemented in two different steps, over a period of two years. In the first step, a survey was carried out during 2013 in order to understand young Italian students' knowledge level, awareness, and feeling with respect to European citizenship and rights. In the second step, interviews were conducted (in 2015) to analyse how social, economic, and political issues (e.g the events that have marked European society in the last two years) changed the feelings and awareness of students of European citizenship. The study uses an integrated methodology that combines different levels of analysis: data extracted from a questionnaire; text from the photo- 
stories; images of the photo-stories and interviews. The methodology allows performance and collection of data and information that maximize the emotional engagement of participants (students) in expressing not only their knowledge and awareness about European citizenship, but also their perception and feeling. The paper is structured as follows. Section 2 provides a discussion on different studies on European citizenship. In Section 3, the methodology is described. Section 4 discusses the results of the first step of the analysis, while Section 5 illustrates the results of the second step. Finally, Section 6 concludes the paper.

\section{Background}

European citizenship is a keyword of contemporary society. It 'integrates the notion of identity, which enables the members of the community of the EU to identify each other as members of the same community within the political processes of European integration' (Karolewski, 2009, p.4). If we consider the concept of national identity, from the socio-psychological point of view, it is understood as 'an affective of opinion as opposed to an evaluative rationality' (Duchesne, 2008). Thus, its knowledge should be taken into account in determining European integration policies. In this perspective, different studies underline an affective relationship between citizenship and European identity (Robyn, 2005; Gillespie \& Laffan, 2006).

There are many studies on European citizenship feeling, but only some of them have examined how young people build their sense of European identity. According to Scalise (2015), since the identity represents one of the EU contemporary challenges, linked to the European integration process, young people deal with this argument and have developed it in different ways, exploring the intersection between politics, culture, and European and national belongings. The study underlined the relevance of the local dimension and socio-economic divide in the shaping of European identity. In particular, the study highlighted the need to implement effective social policies in order to bring Europe closer to its citizens and increase social cohesion in the EU. Agirdag et al. (2012) analysed the impact of individual- and school-level characteristics on children's European identity formation. They found that ethnicity and family socio-economic status (SES) influence how young people build their European identity. Verhaegen and Hooghe (2015) assessed in a correct manner whether knowledge about the EU contributes to the development of a European identity. The study is based on the two different theoretical claims considered, that follows: i) the economic utilitarian approach and ii) the political trust model. Favell (2008) analyses intraEuropean Union migration in three different cities. In particular, Favell's study analyses the mobility, lifestyle, and career opportunities offered by the 
European Union and the barriers that still persist. Moreover, he analyses the new migration trends and forms of urban cosmopolitanism linked to processes of European integration. According to De Wit (2011), 'the creation of a European identity, European citizenship ... are the key catalysts for the political initiatives in education by the European Commission'. More specifically, higher education plays an important role in the creation of European identity (Johansson, 2007). The importance of the Erasmus Programmes in creating a feeling of European citizenship has been underlined in different studies (Sigalas, 2010; Green, 2007; Fligstein, 2008). The same results are shown in Eurobarometer study (2005), which shows that 64 percent of students aged 20-24 'feel attached to Europe', while 59 percent agreed that they 'feel European'. In addition, the Erasmus Student Network (ESN) survey (2008) shows that 62 percent of students perceived the EU country of their Erasmus experience as their second home. More recently, Streitwieser (2011) showed that the majority of Erasmus students identify themselves both as national and European citizens. The study of Van Mol (2011) draws very similar conclusions and findings which show that Erasmus students were usually more engaged in Europe feelings than other people. However, the majority of young people are more interested in politics at a national level. This is more evident in times of crisis, when political activities and actions are focused on their national governments (Fligstein et al., 2011). Other studies found that young people who travel and/or live in other European countries for a period of time are usually more engaged in EU politics. As a consequence, it is necessary for EU Institutions to provide an increasing number of opportunities for young people to travel and make cultural experiences in Europe. According to Meeus (2009, p.1), 'the primary objective of the European Commission, nowadays, is to stimulate further the international mobility of the higher educated within the European Union'. However, some other studies suggest that participating in an Erasmus exchange does not strengthen European identity (Sigalas, 2010; Wilson, 2011). The study of Kuhn (2012) shows that these programmes are not ineffective in promoting European identity, but they are directed at higheducated students, who are already very likely to feel European. Therefore, this experience cannot make a significant difference. On the contrary, loweducated students who might respond strongly by adopting a European identity don't participate in these programmes because they leave school before having this opportunity. Mitchell (2015) observed the significant and positive effect of Erasmus participation on European identity. Concerning the knowledge of European citizenship concept, according to the Standard Eurobarometer 79 (2013), the majority of EU citizens (79 percent) know the term 'citizen of the European Union'. However, there are some differences based on their awareness of the real meaning of this term. 43 percent of the 
respondents are familiar with the term and know what it means; 36 percent of them had heard of the term but ignored its meaning; finally, 22 percent of the respondents asserted they had never heard the term 'European citizenship'. Regarding the knowledge of the rights of European citizens, 36 percent of the respondents feel well informed about the rights. More specifically, the rights they are most familiar with are the 'right to free movement' and 'the right to petition key EU Institutions' (88 percent). On the other hand, 89 percent know 'the right to make a complaint to the European Commission, European Parliament or European Ombudsman'.

\section{Methodology}

A survey in two steps has been carried out to implement our study. The first step was implemented in 2013. The survey involved a genuine sample of Italian students, aged from 18 to 25 years from the North, South, and Central regions of Italy. The sample was chosen on a voluntary basis, and a snow-ball sampling method has been used in amplifying the participation, stimulating a debate, and promoting the sharing and exchange of critical knowledge among Italian students. The involvement of a genuine sample allows the study to focus the analysis on students that are more sensitive to European citizenship. Also, it allows the spread of European citizenship awareness for people that are less sensitive to this topic. Participants were invited to fill in a questionnaire and to participate in a competition called 'You are Europe' promoted by the Italian Government and the European Parliament in order to create photo-stories on European citizens. In the competition, students were invited to send a photo-story on the topic of European citizenship. The aim was to examine the emotions and feelings of young people and to investigate their experiences, which also involves a socio-psychological perspective. The decision to involve students came from the need to engage young people, distributed over the Italian territory (through the network of schools and universities), both with and without experiences of internships in other European countries (e.g. Erasmus or Comenius experiences). Furthermore, it also aims to evaluate the influence of these experiences.

The analysis of the collected data has been developed by integrating three different levels of analysis:

- data resulting from the questionnaire;

- data resulting from the text of the photo-stories;

- data resulting from images of the photo-stories.

The questionnaire was filled in by 307 students, who sent 106 photostories. It should be noted that some photo-stories were the result of collectively produced work (by classes of secondary schools). In total, 67 percent of the responding students were females and 33 percent were males. The majority of the involved students was from the South of Italy (54 percent), 
followed by the North (28 percent), and the Centre (18 percent). Moreover, text and images of the 106 photo-stories presented by the students for the competition have been analysed.

The second survey, implemented in 2015, collected data through ten interviews that involved the winners of the competition. 'Tu sei l'Europa' were the most engaged people among other participants in the first survey together with these European citizenship issues. The aim was to understand if political and economical events that occurred, within two years 2013-2015, changed their identity and feelings about participants who have European citizenship.

In the following sections, the results of the study are described in details.

\section{First Survey Results: How is European Citizenship Perceived?}

This section shows the results of the first survey using a holistic vision of different levels of analysis carried out. It involves the data collected by the questionnaire, the texts, and the images of the photo-stories. Results have been classified according to the different topics resulting from the analysis: (i) European identity feeling, (ii) knowledge on European citizenship concept, (iii) knowledge on rights of European citizens.

\section{European Identity Feeling}

From the analysis of data extracted from the questionnaire, it emerges that the feeling regarding European identity is perceived by Italian young students as an opportunity. In fact, by analysing the students' answers to the question 'How much do you feel yourself as a European citizen?', we observed that: 44 percent 'enough', 28 percent 'much' (29 percent were females and 26 percent were males), 13 percent 'very much' and 'little' (16 percent were males and 11 percent were females). Only 1 percent does not have a European identity feeling. The results per geographical areas indicate that in the South of Italy, this feeling seems to be a bit stronger. In fact, 48 percent of young people from the South say that they feel themselves as European enough, 43 percent from the North, and 36 percent from the Centre. In total, 39 percent of young people from the North, 25 percent from the Centre, and 23 percent from the South answered 'much'. In total, 15 percent of young people from the Centre answered 'very much'. This is together with 14 percent from the South and 12 percent from the North. On the other hand, young people who answered 'few' comprise 24 percent from the Centre, 13 percent from the South, and 6 percent from the North (see Figure 1). Therefore, these data require a reflection on the need to strengthen the sense of belonging to Europe and to consolidate a common feeling. 


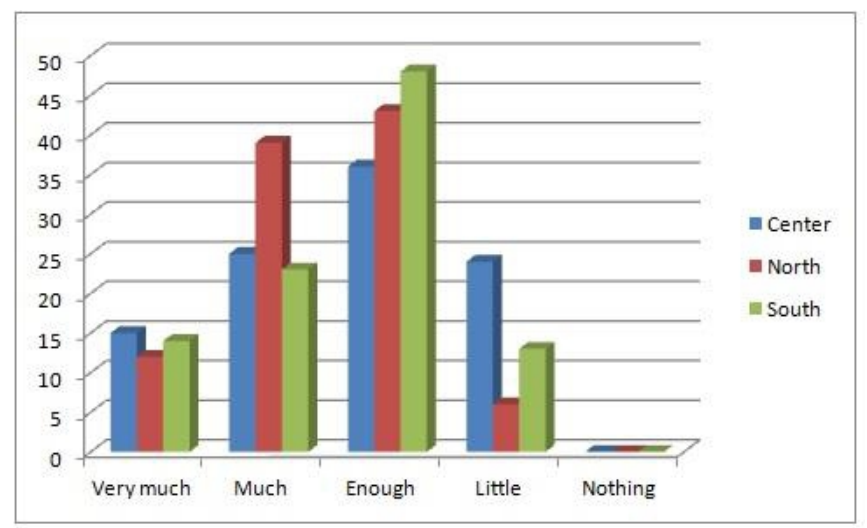

Figure 1. How students feel about European identity

The description of the results related to the analysis of the texts of the photo-stories is connected to the tag-cloud (Figure 2), which contains the key concepts prevailing from the analysis.

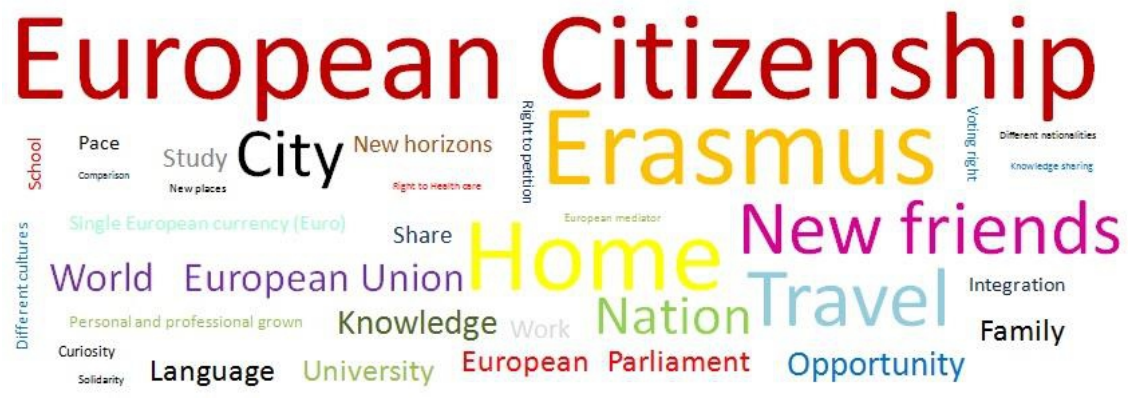

Figure 2. Tag-cloud of photo-stories

The text of the photo-stories underlines that the common feeling of European identity means that people's rights throughout the European territory are perceived to be the same, without discrimination for personal opinions, political orientations, sexual interests, and religion. In particular, the photo-story entitled 'At My Age' refers, through the historical memory of a grandfather, to the issue of freedom and discrimination discussing the indivisible and universal values of the Charter of Rights as expressed in the following comment extracted from the photo-story:

The Charter of Fundamental Rights of the European Union ... is founded on the indivisible, universal values of human dignity, freedom, equality and solidarity. Universal, because apart from some prerogatives, such as the election, this important document extends rights and recognize them not only to European citizens and residents, but to every human being. Indivisible, because they are rights that cannot be separated from each other.

Europe as a common feeling within the same rights is evoked in the 
photo-story titled 'Searching the European Citizen', in which the importance of sharing fundamental rights is highlighted. To enjoy not only the same rights, but also the same opportunities, wherever you are, at the centre as at the periphery of the continent, is the question that emerges from the protagonist of the story. He is a young man on a beach in Calabria (Figure 3), a region of South of Italy. However, scanning the horizon is thinking that:

I am confident that my rights, as a European citizen, will rise from the horizon; these rights will appear on the horizon without... I will leave my native land that, in any case, is part of Europe...I will continue to scan that horizon, confident and proud that sooner or later, I will be a European citizen here, in my native land, not only an Italian citizen

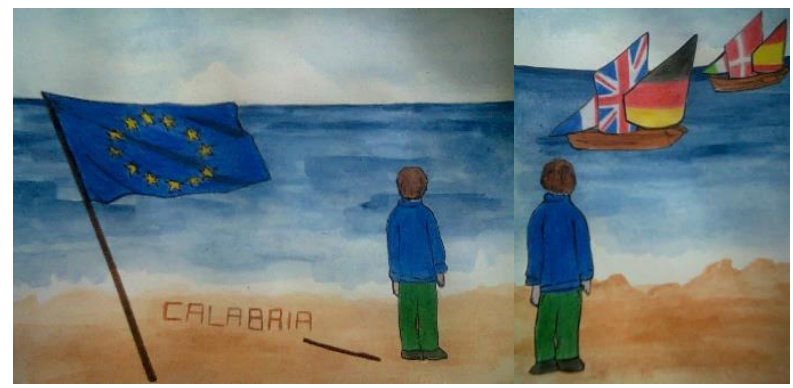

Figure 3. The potentiality of Europe in creating common rights and opportunities

From the images extracted from the photo-stories, we perceived the potentiality of Europe in creating a common and shared space of rights and opportunities for all citizens. Equality, freedom of opinions, religion, sex orientation, and offering the same opportunities in the different areas seem to express what young people mean when they think of European citizenship.

\section{Knowledge of European Citizenship Concept}

The analysis of the questionnaire highlighted a high level of awareness and knowledge of the concept of European citizenship. In fact, 97 percent of students know what it means to be a European citizen, with a small difference between females (99 percent) and males (95 percent). Considering the geographical areas, a greater understanding of the concept of European citizenship comes from students from the North of Italy (99 percent), followed by students from the Centre ( 98 percent) and South ( 96 percent).

In the text associated with the photo-stories, the European citizenship concept is the most frequently cited (as shown in Figure 2). This concept describes a general sense of belonging to Europe, along with the range of opportunities offered by the freedom to cross national borders. The awareness of the opportunities offered by European citizenship mainly concerns knowledge and also the sharing of different cultures that represent the foundation of European citizenship. The ability of cultural interaction and 
exchange among different people in a process of mutual respect and integration to promote the European Union also represents an opportunity for personal and professional growth:

...being European citizens opens a range of opportunities.... it allows

discovering new cultures, developing new skills, learning new languages....

Being European citizens offers new opportunities to students, opens new horizons, promotes integration and solidarity, facilitates new knowledge, forces everyone to learn more than one language to overcome cultural barriers and share different cultures living with different nationalities. To be a European citizen also allows people to visit new places and have personal and professional growth.

From the images extracted from the photo-stories, we perceived (by the symbolism of flags that young people show and share) the importance of cultures and knowledge sharing and the possibility for citizens to discover new horizons beyond the national boundaries.

In the following sections, European citizenship is analysed also with respect to the channel used by students for the knowledge of the European citizenship concept and the feeling of participation in the European citizenship building process.

\section{Channels used for the Knowledge of European Citizenship Concept}

The issues of the European citizenship have been known by European students by using different channels such as school (58 percent), the Internet (15 percent), and TV (percent). However, this is followed by family (4 percent), newspapers ( 3 percent), and friends (1 percent) as shown in Figure 4. Although students are aware of the issues related to European citizenship, 93 percent of the respondents said they would like to increase their knowledge (95 percent of females compared with 89 percent of males). Thus, this percentage indicates a greater propensity of women to learn and get information on these topics. Moreover, 98 percent of the respondents consider that it is very important to carry out initiatives and educational Programmes that focus on the issues of European citizenship. The school is students' favourite environment for these initiatives (58 percent). More specifically, 68 percent of them are students from the South, 48 percent of them come from the Centre, and 47 percent of them come from the North. Another important channel is TV, in particular for students from the Centre (29 percent), from the North (16 percent), and from the South (only 2 percent). The Internet is also indicated by students from the South (15 percent), from the North (10 percent), and from the Centre ( 9 percent). 


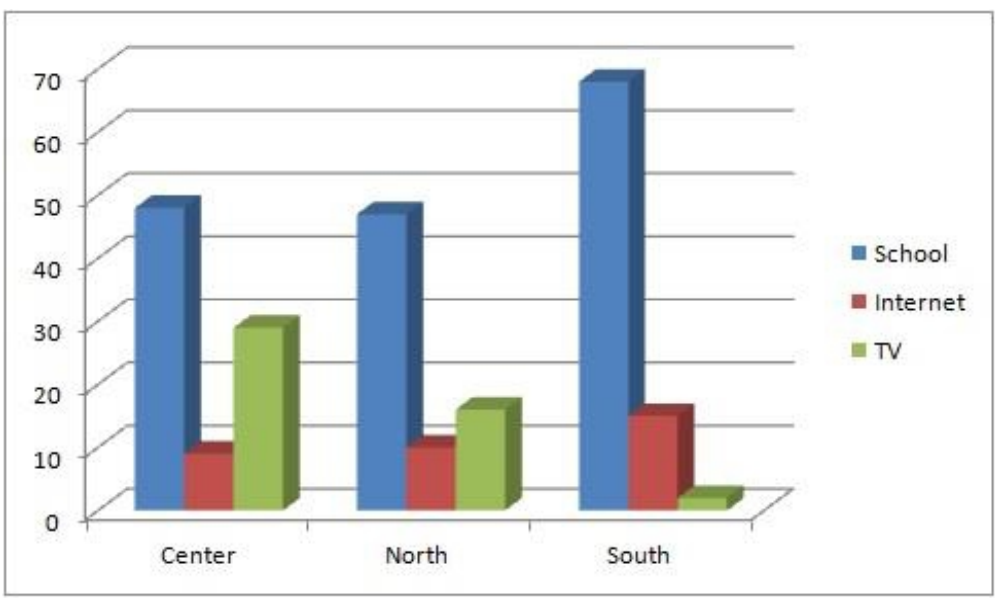

Figure 4. Channels to use for increasing knowledge of the issues of European citizenship

The prevalence of the role of students assigned to the school can be explained by the fact that school is the first community for sharing experiences and knowledge focused on the issues related to European citizenship. On the other hand, schools, together with Institutions and Organizations responsible for corporate communications, not only create training programmes, but also structured initiatives of information for the entire Italian territory. This underlines that students do not only prefer informal communication (e.g. social networks or dialogue with family) to increase their knowledge on the issues of European citizenship, but also tools and places that are already used with a restatement of communication models. This is also confirmed by the only 2 percent of students that consider TV as a privileged channel of communication on the issues related to European citizenship.

The text associated to the photo-stories, underline that school and university are considered by students to be the best 'places' to transmit knowledge about European citizenship, together with tools, such as Comenius and Erasmus Programmes that enable students to directly experience their European citizenship:

....at school I studied Europe, but I never lived and really understood what it means to be a European citizen....one thing is to study Europe in a book, another thing is to live an experience in Europe...

In one of the photo-stories, the importance of other tools such as the Internet is underlined. This tool can contribute to increasing knowledge on the issues related to European citizenship, in particular for all people who could not directly live a European experience. Some photo-stories also express the need to know and understand what it really means to be a European citizen. For example, Odoardo, a fictional character of one of the photo-stories, underlines the difficulties in identifying tools and the path to be followed for building and improving the European citizenship feeling. According to 
Odoardo, the citizens' active involvement is very important, as well as communication and information initiatives that can allow building a European identity. Active involvement, communication, and knowledge initiatives allow people to feel they are part of the same community, thereby creating a good socio-cultural environment.

From the images extracted from the photo-stories, we perceived the importance of school, which is seen as the primary place for communication, information exchanging, and sharing of issues about the European citizenship. Thus, it emerges that it is necessary to carry out initiatives involving citizens in a discussion on these topics.

\section{Participation in European Citizenship Building Process}

Regarding the participation in the process of building the European citizenship, 39 percent of the respondents feel they participate in this process. Females (15 percent) are more involved than males (10 percent). Considering the geographical areas, 44 percent are students from the South, 37 percent are from the Centre, and 32 percent are from the North as shown in Figure 5. The majority of the respondents took part in events and seminars on European citizenship, and/or have experience of the Erasmus Programmes.

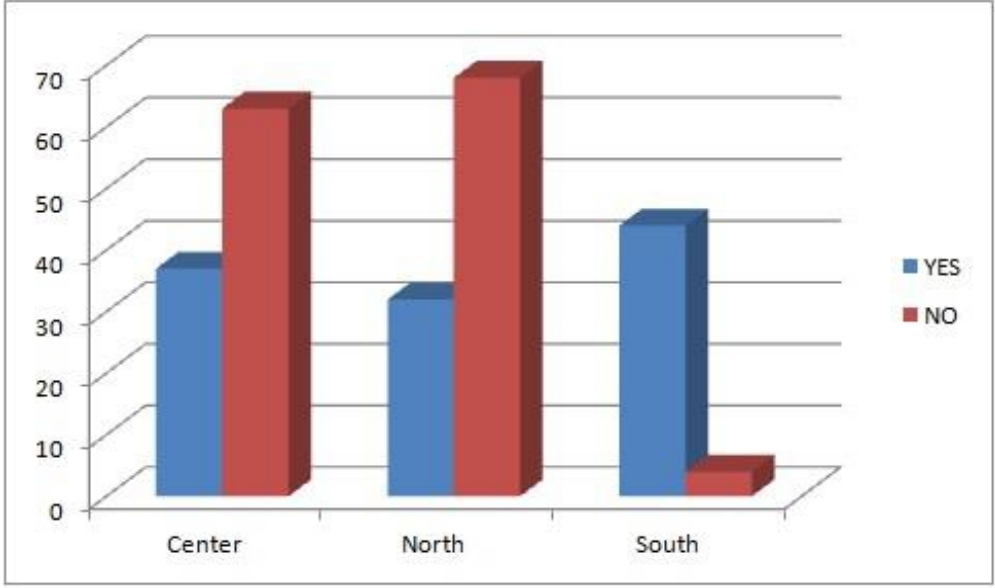

Figure 5. Participation in the process of building the European citizenship

The majority of students (59 percent), particularly those coming from the North (61 percent), 60 percent from the Centre, and 57 percent from the South think that Italian Institutions are not very effective in involving them in the process of building European citizenship. They declare that they want to be involved through greater information on the economic, social, and political rights of the European Union and on related rights. In total, 5 percent of the respondents stated that Italian Institutions are very effective in engaging people in the construction of European citizenship, through the organization of school Programmes and through the provided information. 
The analysis of the text associated to the photo-stories shows a passive attitude on the issues of European citizenship:

... I am a European citizen as I was born in a European Nation. The problem is that I know of the existence of Europe, but I have never perfectly understood what/why a European citizen is ...

The educational programmes that allow studying abroad (like Erasmus) are described by students as tools of great interest and effectiveness to transform passivity into participation. In fact, these tools help people to perceive Europe in their everyday life. The importance of Erasmus and similar experiences is underlined below:

...before my Erasmus experience I had not a clear idea of the meaning

of being a European citizen. At school I had studied Europe, but I never really understood what it meant to be a European citizen. ...

People that directly experienced their daily life in another country of Europe within a cultural path feel themselves as more participative in building Europe.

From the images extracted from the photo-stories, we perceived the importance of sharing daily life with personal and social needs and experiences for building European citizenship and by avoiding to take into account only the economic aspect.

In fact, photo-stories identify the need to complete the process of Europe citizenship building by strengthening social, cultural and political citizenship, in addition to economic factors.

\section{Knowledge of Rights of European Citizens}

European awareness has been also analysed with respect to students' knowledge of the following rights: voting right; right to stay and move within the European member states territory; right to study and/or work in a EU country; right to petition; right of legislative initiative of European citizens; and right to health care. In the following sections, these rights are described in detail.

\section{The Voting Right}

Concerning the voting right, only 14 percent of respondents are not aware of their voting right, compared with 86 percent of them, who know this right very well (with 88 percent of females and 82 percent of males). These data, disaggregated by geographical area, indicate that students of the North and South Italy are more informed (88 percent) than those in the Central area (80 percent).

Despite the good knowledge of the voting right that emerges from the questionnaires, the text associated to the photo-stories show little attention to 
it. The photo-stories convey a formal and detached knowledge of the law, without emphasis or student involvement on this issue:

... it is essential to understand the benefits of being European citizens: we can vote and be elected to the European Parliament...

The images extracted from the photo-stories evoked the action of voting. However, this issue is not so widely discussed, but it is not the consequence of the lack of awareness. It is connected with the lack of engagement of this right in young people's daily life. Images do not describe real life, but they show only something that refers to Institutional and formal action of vote and it does not provide any real life image.

\section{The Right to Stay and Move within the European Member States' Territory}

Questions related to specific rights highlight the importance of the direct experience of students that helps them to build an active awareness of European citizenship. This is evident for the right to stay and move within the European Member States' territory that allows students to have a direct experience of study in EU countries (i.e. Erasmus Programmes).

In total, 99 percent of students answered that they know this right. There are no significant differences among males and females. Only 1 percent of the total number of students from the South of the Italy answered that they do not know about this right. From the Centre of Italy, the percentage is 2 percent, while in the North, all students know this right very well.

The level of awareness of the right to stay and move within the territory of the European Member States is also confirmed in the analysis of the text associated with the photo-stories, where it is the most cited right in relation to the concept of Europeans together with the possibility to meet 'new friends'.

From the images extracted from the photo-stories, we perceived the concept of travelling and freely circulating. Very important emerging issues connected with this right consist of sharing experiences and meeting new friends.

\section{The Right to Study and / or Work in an EU Country}

Strictly linked to the right to stay and move within the European Member States territory is the right to study and/or work in an EU country. Only 9 percent of the respondents said that they are not aware that academic and professional qualifications are recognized in any Member State. These data by gender indicate that 92 percent of females are aware of this, compared with 87 percent of males. Data by geographic areas indicate that there are no significant differences among North, South, and the Centre of Italy. But how many of the respondents are favourable to the idea of living an experience in a European context? In total, 91 percent of the respondents expressed their availability. In addition, 93 percent of them said they want to study in a 
European country different from Italy. There were no significant differences among the different geographical areas. A total of 7 percent of the respondents say that they do not want to study in a European country different from Italy, while 87 percent of them would like to work in a European country other than Italy. A sense of belonging to Europe emerges. Hence, belonging is towards Italy while Europe is seen as an opportunity that Italy (where students belong) does not offer. In total, 13 percent of them do not want to work in a European country other than Italy. In particular, young people from the Centre and the South of Italy (89 percent) stated that they are willing to work in a European country, compared with 84 percent of young people from the North of Italy. By the answers to the questionnaire, it emerges that the proportion of people willing to work in a European country different from Italy falls to 87 percent (compared with 93 percent of those willing to study in a European country different from Italy). Those who have expressed their willingness to work in a European country different from Italy gave some motivations underlining the importance of both comparing and sharing different experiences, the greater opportunities that other European countries can offer, acquiring new knowledge and experience, and then returning to Italy and using the new knowledge 'at home'.

The lack of a common language is perceived as a serious obstacle for sharing experiences and for mutual understanding. The same difficulty was necessary to overcome in many national states in the past centuries, for using a common language and not only dialects of the different regions.

According to some photo-stories, living, studying, and working every day in a different EU country helps to enhance the feeling of European citizenship and can offer new opportunities. But studying or working in a different European country is not always considered simple. For example, some photo-stories have highlighted the need for greater clarity and information regarding the recognition of qualifications in the Member States.

From the images extracted from the photo-stories, it is possible to see that students perceive the opportunities of sharing an experience of study or work in other European countries. It helps to build a European common feeling unifying cultures and uses from different countries with the aim of building a new common knowledge.

\section{The Right to Petition}

Regarding the right to petition, 67 percent of the respondents have a good knowledge of the right to petition to the European Parliament (60 percent males and 71 percent females); 33 percent ignore this right. There are no significant differences among the North, South, and Centre of Italy. Within the photo-stories, the right to petition is described as a fundamental right that underlines the active participation of citizens in the political and social life of 
the European Union. However, this right is mentioned only in the text of two photo-stories, although it is known by a large part of the students. This is due to the fact that this right is not exercised in everyday life and thus, it can only be experienced with a certain detachment. However, the photo-stories described this as a fundamental right:

....any EU citizen or resident in a European Member State may individually or with other citizens, submit a petition to the European Parliament on an issue that falls within the scope of the European Union...

\section{The Right of the Legislative Initiative of European Citizens}

Regarding the right of legislative initiative of European citizens, 63 percent of the respondents know the possibility for European citizens to promote legislative initiatives to the European Commission. There are no significant differences between males and females among the North, South, and Centre of Italy.

In the texts associated with one of the photo-stories, this right is described in general terms and without specific reference to direct or mediated experiences:

...to be part of the EU means ..... right of legislative initiative...

The awareness of this right is not confirmed by the images. In fact, no significant images have been extracted from the photo-stories. The low sociopsychological perception of the right of legislative initiative from the students is probably due to the lack of direct experience of this right.

\section{The Right to Health Care}

Regarding the right of health care, 93 percent of the students seem to know their right to health care within the European Member States. Among them, 95 percent are females and 90 percent are males. Considering the geographical areas, there are no significant differences among the North, South, and Centre of Italy.

The level of awareness of the right to health care is also confirmed in the analysis of the texts associated to the photo-stories. Students seem to have had personal experiences and real enjoyment of this right:

... in Warsaw I tested the effectiveness of the European health insurance! I had never entered into an operating theatre in Italy...for me was the first time...

From the images extracted from the photo-stories, we perceived the importance for citizens to receive health care assistance in all European Member States. That is, images are related to personal experiences. 


\section{Second Survey: How did European Citizenship Perception Change in the Years 2013-2015?}

In the second step of the survey, interviews were conducted with the winners of the competition after two years with respect to the first step. The results underline and affirm again the need of an increased European citizens' awareness with respect to their rights and to a Europe that is still perceived as distant. Even in their awareness of the importance of Europe and its citizenship, responders retained a largely low perception of the European identity, and a Europe that is still too far from people.

According to the opinions of some people interviewed, this situation is influenced by the fact that many young people did not have the opportunity to live training/working experiences outside their country. Others stressed their need to feel themselves as part of the European Community regardless of their experiences of study or work in other European countries. For some students, their feeling of European citizenship is linked to the opportunities of democracy and participation, and it is perceived as a necessary condition for the existence of the European Union.

The financial turbulences of the last years have produced a political and social fracture, which can be redressed only by strengthening common political and social actions, for example, aiming to build a single taxation, a European foreign policy for peace, etc.

The Greek crisis of 2015 (and the Mediterranean economies) showed that citizens from countries with major economic problems generally perceive a Europe of rights as a theoretical entity and far removed from daily life, more than people living in a country that is economically stronger.

This crisis and the great migrations resulting from theatres of war around Europe have highlighted both economic and political problems and weaknesses of the European system. It needs to be strengthened, improving people's involvement and participation. There is the need for a political Europe stronger and able to be the Europe of the citizens, to become the Europe of citizenship.

From the survey, it emerges that the social, economic or political choices and their consequences have not changed students' perception in Italy in the period 2013-2015. The turbulences did not decreased their sense of European citizenship, but have negatively influenced the confidence that they placed in some people covering some positions of responsibility and that produced such turbulences. According to most of the students, in considering the difficulties of the current historical moment, the political Institutions should implement measures to increase the cohesion among all states of the European Union. For example, all states should implement common political and economical actions to address the issue of immigration. On the contrary, each single State should implement its own action with some guidelines at the 
level of the European Union that appears to be unsatisfactory with respect to the extent of the immigration phenomenon. Another example is represented by the issue of civil rights: there are some asymmetries among the different States of the Union with respect to civil rights, such as, for example, the right to get married for people of the same-sex.

Some students underline the importance of actions such as: Erasmus projects, European trades, and youth initiatives for strengthening the economical, social, and territorial cohesion. Moreover, they underlined the importance of communication plans and strategies that have to be most appropriate to the target audience in order to disseminate and reinforce the sense of citizenship and European identity. In particular, TV programmes should enhance the perception of the benefits linked to a European lifestyle. It is also suggested that tools and initiatives should be developed to enhance citizen participation and discussion (e.g. 'Tu sei l'Europa').

Finally, students suggested both increasing the role of schools in teaching European rights to new generations and intensifying the action using all mass media ( $\mathrm{TV}$, radio, web and especially social networks) to communicate with adults and elderly people.

\section{Discussions and Conclusion}

The relevance of the study mainly returns the socio-psychological dimension of Italian students with respect to the European citizenship, identity, and rights. The innovativeness of the study consists of the methodology used. It is an integrated methodology that allows the two research questions to be answered that were at the base of the analysis: 'How do Italian students perceive the European citizenship identity?' and 'How well do Italian students know the European citizenship concept and the related rights?' Table 1 summarises the most relevant results. In particular, these results have been classified according to positive and negative feelings of European citizenship and identity, and how to improve them and the level of knowledge of European citizens' rights. 


\begin{tabular}{|c|c|}
\hline \multicolumn{2}{|c|}{ PSYCOLOGICAL FEELING: "how the Italian students perceive the European identity?" } \\
\hline Positive feeling & Negative feeling \\
\hline $\begin{array}{l}\text { Italian young students feel themselves as European. They believe } \\
\text { that Europe provides a common and shared space of rights and } \\
\text { opportunities for all citizens. For students European identity firstly } \\
\text { means that people rights are perceived to be the same, through the } \\
\text { entire European territory, without discrimination for personal } \\
\text { opinions and, political, sexual and religious orientation. }\end{array}$ & $\begin{array}{l}\text { Some photo-stories underlined the need to reinforce the feeling of } \\
\text { European citizenship, as currently in some areas at the periphery } \\
\text { of the continent this is not so evident. Everywhere in the continent } \\
\text { people should live feeling themselves as in the hearth of Europe. }\end{array}$ \\
\hline \multicolumn{2}{|c|}{ KNOWLEDGE: "how students know the european citizenship concept and the related rights?" } \\
\hline \multicolumn{2}{|c|}{ Knowledge on European citizenship concept } \\
\hline Actual Knowledge & \begin{tabular}{|c|} 
How improving knowledge and feeling? \\
\end{tabular} \\
\hline $\begin{array}{l}\text { High level of awareness and knowledge of the European } \\
\text { citizenship concept. The awareness of the opportunities offered by } \\
\text { European citizenship mainly concems the sharing of different } \\
\text { cultures that represent the foundation of the European citizenship. } \\
\text { Some students took part in events and seminars on European } \\
\text { citizenship, and/or have experienced Erasmus Programmes. }\end{array}$ & $\begin{array}{l}\text { Even if students feel to have a good knowledge of the European } \\
\text { citizenship concept, they believe that is necessary to improve this } \\
\text { knowledge and this feeling. } \\
\text { More initiatives are asked by students to enhance participation in } \\
\text { European Citizenship building process. More in detail, students } \\
\text { consider that it is very important to carry out initiatives and } \\
\text { educational Programmes focusing on European citizenship. } \\
\text { School is the students' favorite environment for these initiatives. }\end{array}$ \\
\hline \multicolumn{2}{|c|}{ Knowledge of rights of European citizens } \\
\hline Good Knowledge & \begin{tabular}{|c|} 
Poor knowledge \\
\end{tabular} \\
\hline $\begin{array}{l}\text { Good knowledge of the rights of European citizens. In particular it } \\
\text { was observed a high level of awareness for the right to stay and } \\
\text { move within the European Member States teritory and the right to } \\
\text { Health Care. This high level of awareness is linked to the student's } \\
\text { personal experiences and real enjoyment of these rights (a large } \\
\text { part of them enjoyed Erasmus stages). }\end{array}$ & $\begin{array}{l}\text { Unlike right to vote, the students have little awareness of the right } \\
\text { to petition and the right to legislative initiative of European } \\
\text { Citizens. In any case it is a formal and detached knowledge } \\
\text { probably due to the lack of specific direct student's experiences. }\end{array}$ \\
\hline
\end{tabular}

Table 1. Main results of the analysis

Table 1 shows that the European identity is perceived as the citizens' feeling of belonging to the same community (Europe) with equal rights and duties. From the study, it emerges that more institutional information and communication initiatives are necessary to enhance the European identity feeling and knowledge of European citizenship and their relative rights. In fact, some photo-stories express the need to know and understand what it really means to be a European citizen. For this purpose, the active engagement of students through communication and information initiatives that can improve the building process of a European identity is very important. However, according to Biesta et al. (2009), 'a more appropriate and effective response to all the concerns about young people's citizenship and the future of democracy' and citizenship learning should lie on a concern for the actual condition of young people's citizenship, rather than on the mere improvement of the communication and information initiatives. In this sense, the active involvement can allow students to feel themselves as part of the same community creating a good socio-cultural environment. Knowledge about European citizenship is good when students had a direct 
experience. In fact, with respect to the knowledge of the rights related to the European citizenship, the right to freely move themselves emerges as largely acquired and heard. Questionnaires and photo-stories, in fact, underline that travelling freely is crucial to promote the meeting, sharing, and building a community of people. Nevertheless, the involved students underlined that citizenship firstly implies asserting their rights throughout the European territory. An increased awareness of European citizens of their rights means to approach a Europe that is still perceived distant. Awareness of these rights was built by a direct experience or knowledge built through the influence of friends, relatives, and/or Institutions. Citizens' opportunities of participation in the life of European Institutions seem to be less known. Finally, the study underlined that the knowledge of rights is fundamental and it is the first step for exercising them. An idea of Europe as something too far from the life of people emerges two years after the first survey. The perception of distance seems to be further emphasized by the financial and political turbulences that have produced a large social divide; but this also can be related to the distance of citizens from Institutional places of policy. In fact, a lack of trust towards Institutions shows that the interviewed students are not carrying out sufficient actions to increase the cohesion of people in Europe. The survey highlighted a lack of democracy within the European Union as a common ideal place of participation and common life. Europe still seems to be perceived as a set of States that are financially and politically unaligned and independent. Also, the knowledge of European rights has not changed from 2013 to 2015. It is underlined that there is a need to increase the knowledge and awareness of European rights. In particular, students suggested increasing the role of schools in teaching the rights to new generations and intensifying the action of all the mass media (TV, radio, web and especially social networks) to communicate with adults and elderly people.

\section{Acknowledgement}

This work was support by the Management Partnership Agreement of the European Commission, the European Parliament, and the Presidency of the Council of Ministers' Department for European policies in collaboration with the Ministry of Foreign Affairs.

\section{References:}

1. Agirdag, O., Huyst, P., \& Van Houtte, M. (2012). Determinants of the Formation of a European Identity among Children: Individual- and School-Level Influences. JCMS: Journal of Common Market Studies, 50(2): 198-213. 
2. Barbalet, J. M. (1988) Citizenship. Milton Keynes: Open University Press.

3. Biesta, G., Lawy, R., \& Kelly, N. (2009). Understanding young people's citizenship learning in everyday life The role of contexts, relationships and dispositions. Education, citizenship and social justice, 4(1), 5-24.

4. Bianchi, G. E. (2011). Italiani nuovi o nuova Italia? Citizenship and attitudes towards the second generation in contemporary Italy. Journal of Modern Italian Studies, 16(3), 321-333.

5. Brubaker, R. \&Cooper, F. (2000). Beyond 'identity'. Theory and Society, 29(1): 1-47.

6. De Wit, H. (2011). Europe: Misconceptions about Internationalisation. University World News. Retrieved from http://www.universityworldnews.com/article.php?story=2011040818 1353543

7. Duchesne, S. (2008). Waiting for a European Identity... Reflections on the Process of Identification with Europe. Perspectives on European Politics and Society, 9(4): 397-410.

8. Erasmus Student Network AISBL (2008). Exchanging Cultures. Results of ESNSurvey '08. Brussels, Belgium.

9. Eurobarometer (2005). Youth Takes the Floor-Young Europeans' Concerns and Expectations as to the Development of the European Union. Brussels, Belgium: European Commission.

10. Eurobarometer 79 available at http://ec.europa.eu/public_opinion/archives/eb_arch_en.htm.

11. Favell (2008). Eurostars and Eurocities: Free Movement and Mobility in an Integrating Europe. Wiley-Blackwell, Hoboken.

12. Fligstein, N. (2008). Euroclash: The EU, European Identity, and the Future of Europe. Oxford: Oxford University Press.

13. Fligstein, N., Polyakova, A., \& Sandholtz, W. (2011). European Integration, Nationalism and European Identity, Journal of Common Market Studies, 50(S1): 106-122.

14. Gillespie, P. \& Laffan, B. (2006). European Identity: Theory and Empirics, in: M. Cini and A. K. Bourne (eds) Palgrave Advances in European Union Studies, 131-150. Basingstoke, UK: Palgrave Macmillan.

15. Green, D. (2007). The Europeans: Political Identity in an Emerging Polity. Boulder: Lunne Rienner.

16. Johansson, J. (2007). Learning To Be (come) A Good European: A Critical Analysis of the Official European Union Discourse on European Identity and Higher Education. Linköping: Linköping University. 
17. Karolewski, I. P. (2009). Citizenship and collective identity in Europe. Routledge.

18. Kuhn, T. (2012). Why Educational Exchange Programmes Miss Their Mark: Cross-Border Mobility, Education and European Identity. JCMS: Journal of Common Market Studies, 50(6): 994-1010.

19. Meeus, B. (2009). Adrian Favell, Eurostars and Eurocities. Free movement and mobility in an integrating Europe. Blackwell Publishing, Belgeo.

20. Mitchell, K. (2015). Rethinking the 'Erasmus Effect' on European Identity. JCMS: Journal of Common Market Studies, 53(2): 330-348.

21. Robyn, R. (ed.) (2005). The Changing Face of European Identity. London and New York: Routledge.

22. Scalise, G. (2015). The Narrative Construction of European Identity. Meanings of Europe 'from below'. European Societies, 17(4), 593614.

23. Sigalas, E. (2010). Cross-border Mobility and European Identity: The Effectiveness of Intergroup Contact during the ERASMUS Year Abroad. European Union Politics, 11(2): 241-265.

24. Soysal, Y. N. (2000). Citizenship and Identity: Living in Diasporas in Post-war Europe?, Ethnic and Racial Studies, 23(1): 1-15.

25. Streitwieser, B. (2011). Erasmus Mobility Students and Conceptions of National, Regional and Global Citizenship Identity, Working Paper No. 11-001, Center for Global Engagement Working Paper Series, The Roberta Buffett Center for International and Comparative Studies, Northwestern University, August.

26. Van Mol, C. (2011). The Influence of European Student Mobility on European Identity and Subsequent Migration Behaviour, in F. Dervin (ed.). Analysing the Consequences of Academic Mobility and Migration. Newcastle: Cambridge Scholars Publishing, 29-50.

27. Verhaegen, S. \& Hooghe, M. (2015). Does More Knowledge about the European Union Lead to a Stronger European Identity? A Comparative Analysis among Adolescents in 21 European Member States. Innovation: The European Journal of Social Science Research, 28(2): 127-146.

28. Wilson, I. (2011). What Should We Expect of 'Erasmus Generations'?. JCMS: Journal of Common Market Studies, 49(5): 1113-1140. 